\title{
Hydrochemical evaluation of surface water quality and pollution source apportionment in the Luan River basin, China
}

\author{
Huiliang Wang, Xuyong Li and Ying Xie
}

\begin{abstract}
In the context of rapid economic growth in China, hydrochemical characteristics of stream water quality are being influenced by a variety of natural and anthropogenic inputs. We determined 10 hydrochemical parameters of the surface water at 29 monitoring sites in the Luan River basin of northern China during 2007-2009. Water quality hydrochemistry was evaluated using fuzzy comprehensive analysis based on the National Surface Water Environmental Quality Standards of China. Our results showed that 14 sites were classified as 'meeting standard (MS)' while the other 15 sites were classified 'non-meeting standard (NS)'. According to principal component analysis, four potential pollution sources were identified that explained $80.6 \%$ of the total variance among these MS sites, and three potential pollution sources that explained $78.3 \%$ of the total variance among these NS sites. Furthermore, multi-linear regression of the absolute principal component scores was used to estimate contributions from identified pollution sources. Most water pollution variables were influenced primarily by municipal sewage and non-point pollution in MS sites. In NS sites, chemical industry wastewater pollution dominated. Pollution in the main stream was more serious than that in the small tributaries. Our findings provide useful information for developing better pollution control strategies for the Luan River.

Key words | fuzzy comprehensive assessment, hydrochemical parameters, multi-linear regression of the absolute principal component scores, stream water quality
\end{abstract}

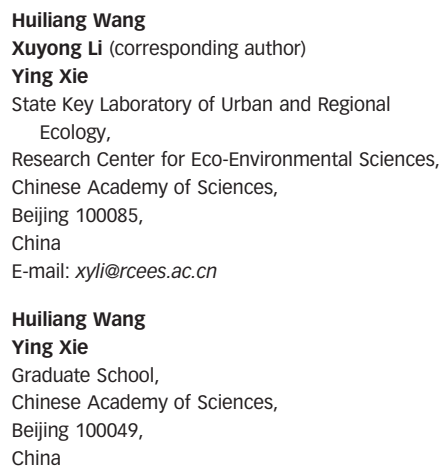

\section{INTRODUCTION}

Rivers are among the most vulnerable water bodies to pollution because of their role in carrying off municipal and industrial wastewater as well as run-off from agricultural and urban lands (Singh et al. 2005). One critical step to control river pollution effectively is to analyse the characterisation of the water quality and apportion the pollution source (Kolovos et al. 2002; Huang et al. 2009). A popular method to tackle this challenge is the use of stressor-specific bio-indicators based on biological and ecological traits (Beketov \& Liess 2008). However, various mathematical techniques based on hydrochemical analysis are methods that can also be used.

Fuzzy comprehensive assessment (FCA) has been used successfully for hydrochemical evaluation of water quality (Shen et al. 2005; Huang et al. 2009). In addition, statistical methods such as principal component analysis (PCA) and multi-linear regression of the absolute principal component scores (APCS-MLR) have been effectively applied to the analysis of water quality and identification of the pollution sources (Simeonov et al. 2003; Singh et al. 2005; Shrestha \& Kazama 2007; Huang et al. 2009). These single multivariate methods were successfully applied to analyse spatialtemporal variations of surface water quality, but comprehensive application of FCA linking different statistical techniques, which will be helpful in the hydrochemical evaluation of water quality and apportioning pollution sources, has not been fully explored in studies of stream water quality.

The Luan River is the main water source of the cities of Tianjin and Tangshan in northern China. In recent years, with rapid economy growth, the river water quality has been seriously degraded and most sectors of the Luan 
River do not meet drinking water standards. The water pollution of the Luan River Basin (LRB) represents the common situation of most rivers in the north of China, including various types and spatial patterns of pollutants, processes and multiple sources. In order to develop and improve pollution control strategies, hydrochemical evaluation of the water quality and apportionment of pollution sources are needed.

In this study, our objectives were: (1) to evaluate the hydrochemistry of surface water quality based on analysis of three years of data (2007-2009) from 29 monitoring sites in the LRB using FCA; (2) to identify and apportion the major natural and anthropogenic factors influencing water pollution in the main stream and tributaries of the LRB using PCA and APCS-MLR. These objectives explore the feasibility and effectiveness of the comprehensive application of FCA and different statistical techniques to pollution control.

\section{METHODS AND MATERIALS}

\section{Study area and monitoring data}

The LRB is located between $115^{\circ} 30^{\prime}$ and $119^{\circ} 45^{\prime}$ east longitude, and $39^{\circ} 10^{\prime}$ to $42^{\circ} 40^{\prime}$ north latitude. The Luan River is
888 kilometres long with a drainage area of 44,070 square kilometres, of which $98 \%$ is mountainous (Figure 1). The LRB is divided into an upstream and downstream region by the Panjiakou and Daheiding reservoirs. In the downstream region of the $\mathrm{LRB}$, there is almost no water in the river, and therefore this paper focussed on the upstream region.

The water quality monitoring centre of the Chengde Branch of the Hebei Provincial Survey Bureau of Hydrology \& Water Resources (SBHWR) monitored 10 hydrochemical parameters monthly over 3 years (20072009) at 29 monitoring sites. These sites were distributed within the study area and covered the main river channel and associated tributaries (Figure 1). The hydrochemical parameters included dissolved oxygen (DO), potassium permanganate index $\left(\mathrm{COD}_{\mathrm{Mn}}\right)$, ammoniacal nitrogen $\left(\mathrm{NH}_{3}-\mathrm{N}\right)$, total phosphorus (TP), chemical oxygen demand (COD), chromium $\left(\mathrm{Cr}^{6+}\right)$, total mercury $(\mathrm{Hg})$, total lead $(\mathrm{Pb})$, fluoride $\left(\mathrm{F}^{-}\right)$, and volatile phenol $(\mathrm{V}-\mathrm{ArOH})$. The following data pre-treatment methods were used: (1) Missing data were estimated as average values from corresponding datasets (Zhou et al. 2007). In the LRB, the water at three top upstream sites always freezes in winter, so these missing data were estimated as average values. (2) In the LRB, the content of heavy metals in water is low and cannot be detected. Values below limits were replaced by their limits

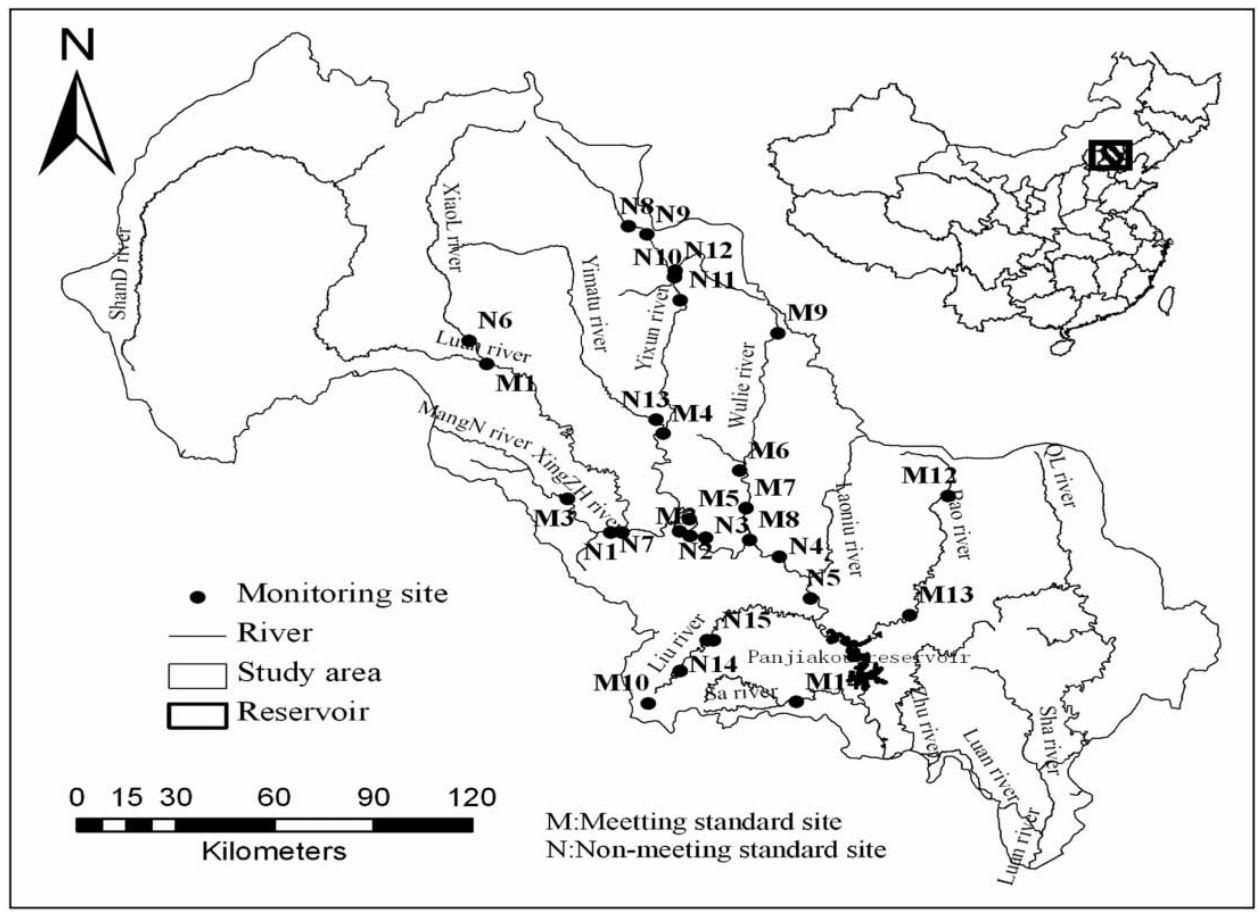

Figure 1 | Study area and water quality monitoring sites. 
of detection (Farnham et al. 2002). The statistical summaries of the 3-year hydrochemical data (10,440 observations) are presented in Table 1.

\section{Statistical methods}

FCA is the process of evaluating an objective by utilising fuzzy set theory, which comprehensively considers the contributions of multiple related indicators based on weights, and decreases the fuzziness by using membership functions (Wang et al. 2003). The procedures of FCA include selecting assessment parameters, building assessment criteria and membership functions of each assessment parameter, then calculating the membership function matrix and the weights matrix, and finally conducting assessment using a fuzzy algorithm (for mathematical details of FCA, see Shen et al. (2005) and Huang et al. (2009)). In this paper, 10 variables, including $\mathrm{DO}, \mathrm{NH}_{3}-\mathrm{N}, \mathrm{COD}_{\mathrm{Mn}}, \mathrm{TP}, \mathrm{COD}, \mathrm{Cr}^{6+}, \mathrm{Pb}, \mathrm{Hg}$, $\mathrm{F}^{-}$and $\mathrm{V}-\mathrm{ArOH}$, were selected for hydrochemical evaluation of water quality. The assessment criteria of five water quality grades were derived from GB3838-2002 (Table 1).

PCA is the statistical method that is used to reduce variable dimension (Thurston \& Spengler I985). PCA is used to reduce the dimensionality of a data set consisting of a large number of interrelated variables, while retaining as much as possible of the variation present in the data set. This is achieved by transforming to a new set of variables, the principal components, which are uncorrelated, and which are ranked with their importance in explaining the contributions to the independent variable so that the first few retain most of the variation present in all of the original variables (Jolliffe 2002). The computational procedure of PCA can be divided into three steps: (1) singular value decomposition; (2) dimension determination; (3) factor rotation. The varimax rotated method is commonly used in PCA (Statheropoulos et al. 1998; Sindosi et al. 2003).

APCS-MLR, or multiple linear regressions with the denormalised APCS values produced by PCA, is a receptor model applied to estimate the contribution of each pollution source to the total concentration (Simeonov et al. 2003; Zhou et al. 2007). Briefly, APCS-MLR calculates the source profiles and source strengths in absolute concentration units using data measured at the receptor site. Regressing the pollution variable concentration data on these APCS gives estimates of the coefficients that convert the APCS into pollutant source contributions from each source for each sample.

Mathematical details of PCA and APCS-MLR can be found in Thurston \& Spengler (I985). In this study, SPSS 16.0 for Windows (SPSS Inc., Chicago, IL) was used to perform the PCA and APCS-MLR analyses.

\section{RESULTS AND DISCUSSION}

\section{Hydrochemical evaluation of surface water quality in the LRB}

Using FCA, we evaluated hydrochemical characteristics for all monitoring sites (Table 2). According to the GB38382002, the LRB was divided into two categories: meeting standard (MS), which included the sites that were classified

Table 1 | Statistical summary of hydrochemical variables of the LRB during 2007-2009 and the Environmental Guideline of National Quality Standards for Surface Waters, China $(\mathrm{GB} 3838-2002)^{\mathrm{a}}$

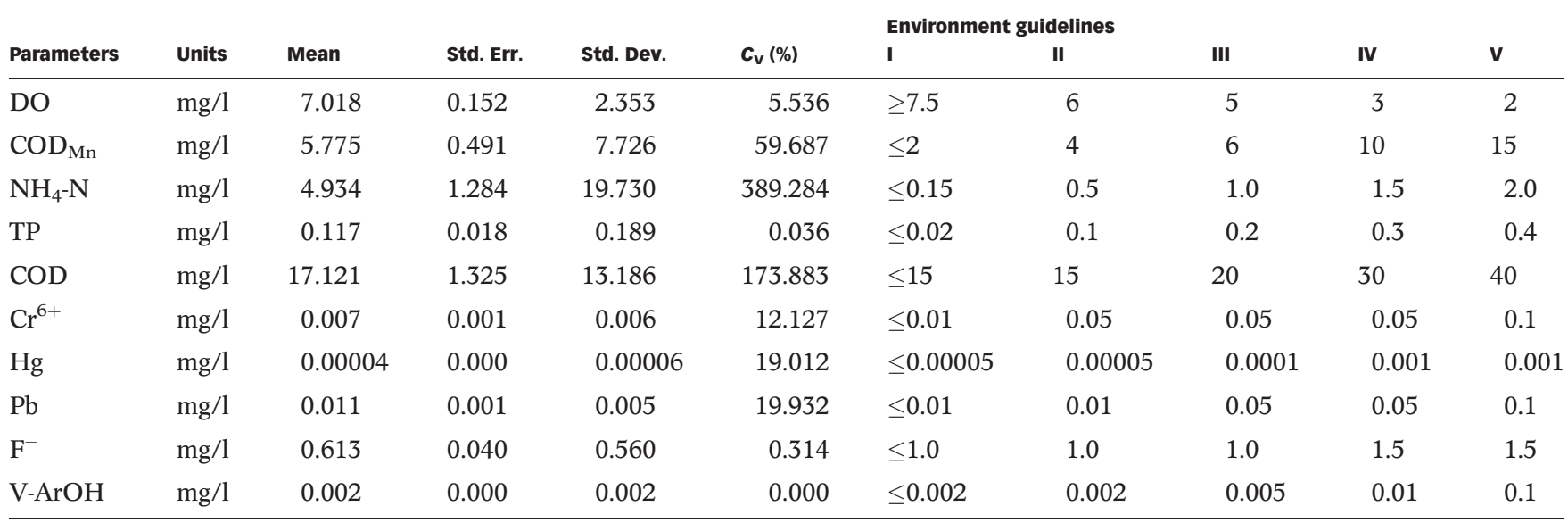

${ }^{\mathrm{a}} \mathrm{Std}$. Err., standard error; Std. Dev., standard deviation; $C_{\mathrm{V}}(\%)$, coefficient of variation in percentage. 
Table 2 | Results of hydrochemical evaluation and their classification of water quality ${ }^{\text {a }}$

\begin{tabular}{|c|c|c|c|c|c|c|}
\hline Site & I & II & III & IV & v & Result \\
\hline M1 & 0.201 & 0.195 & 0.129 & 0.000 & 0.000 & I \\
\hline M2 & 0.152 & 0.163 & 0.285 & 0.285 & 0.000 & III \\
\hline M3 & 0.262 & 0.192 & 0.110 & 0.110 & 0.000 & I \\
\hline M4 & 0.162 & 0.162 & 0.257 & 0.257 & 0.000 & III \\
\hline M5 & 0.161 & 0.175 & 0.253 & 0.200 & 0.000 & III \\
\hline M6 & 0.220 & 0.139 & 0.000 & 0.000 & 0.000 & I \\
\hline M7 & 1.193 & 0.225 & 0.186 & 0.000 & 0.000 & II \\
\hline M8 & 0.131 & 0.131 & 0.248 & 0.248 & 0.000 & III \\
\hline M9 & 0.175 & 0.267 & 0.042 & 0.000 & 0.000 & II \\
\hline M10 & 0.049 & 0.171 & 0.293 & 0.293 & 0.000 & III \\
\hline M11 & 0.192 & 0.192 & 0.227 & 0.227 & 0.000 & III \\
\hline M12 & 0.209 & 0.211 & 0.187 & 0.000 & 0.000 & II \\
\hline M13 & 0.206 & 0.344 & 0.167 & 0.000 & 0.000 & II \\
\hline M14 & 0.133 & 0.297 & 0.106 & 0.106 & 0.000 & II \\
\hline N1 & 0.148 & 0.148 & 0.213 & 0.327 & 0.300 & IV \\
\hline N2 & 0.048 & 0.078 & 0.113 & 0.188 & 0.188 & IV \\
\hline N3 & 0.141 & 0.117 & 0.000 & 0.435 & 0.300 & IV \\
\hline N4 & 0.054 & 0.057 & 0.081 & 0.081 & 0.719 & $\mathrm{~V}$ \\
\hline N5 & 0.069 & 0.095 & 0.122 & 0.122 & 0.561 & $\mathrm{~V}$ \\
\hline N6 & 0.171 & 0.106 & 0.420 & 0.431 & 0.000 & IV \\
\hline N7 & 0.119 & 0.107 & 0.027 & 0.280 & 0.397 & V \\
\hline N8 & 0.026 & 0.004 & 0.091 & 0.094 & 0.342 & $\mathrm{~V}$ \\
\hline N9 & 0.035 & 0.004 & 0.082 & 0.109 & 0.564 & $\mathrm{~V}$ \\
\hline N10 & 0.082 & 0.141 & 0.169 & 0.169 & 0.388 & $\mathrm{~V}$ \\
\hline N11 & 0.003 & 0.008 & 0.008 & 0.017 & 0.907 & $\mathrm{~V}$ \\
\hline N12 & 0.095 & 0.089 & 0.033 & 0.297 & 0.351 & $\mathrm{~V}$ \\
\hline N13 & 0.146 & 0.146 & 0.229 & 0.032 & 0.000 & IV \\
\hline N14 & 0.159 & 0.148 & 0.300 & 0.381 & 0.000 & IV \\
\hline N15 & 0.099 & 0.084 & 0.000 & 0.000 & 0.362 & $\mathrm{~V}$ \\
\hline
\end{tabular}

aM1-M14, meeting standard (MS) sites; N1-N15, non-meeting standard (NS) sites.

as classes I, II and III, and non-meeting standard (NS) including the sites that were classified as classes IV and $\mathrm{V}$. There were 14 MS monitoring sites, and 15 NS monitoring sites (Table 2, Figure 1).

Our FCA results indicated that the Xiaoluan, Yixun, and Liu rivers as well as the main stream of the Luan River were badly polluted. The Sa, Bao, Xingzhou and Wulie rivers were lightly polluted. Pollution in the main stream was more serious than that in the small tributaries. The factors that caused main stream pollution were complex. Although pollutant discharges from small tributaries partly contributed to the main stream pollution, the major pollution sources were from direct discharges to the main stream from non-point sources (such as agricultural and urban runoff), and from point sources (such as industrial wastewater and municipal sewage) along the main stream. The spatial variation of water quality in the LRB was a peculiarity and was different from that of other studies. Shrestha \& Kazama (2007) found that in the Fuji River Basin of Japan, lower level of pollution (LP) occurred mainly at upstream sites and higher level of pollution (HP) mainly at downstream sites. Huang et al. (2009) revealed that the LP sites were located primarily in the main river channel and the large tributaries, whereas medium level of pollution and HP sites were in small tributaries. The result of FCA was in line with the actual situation of the study area. This showed the appropriateness and the effectiveness of this method. However, it was difficult to assign a latent variable (a pollution index) in the FCA analysis. In FCA, hydrochemical characteristics related indices, such as nutrient index, heavy metal index and toxic compound index were assigned as latent variables. The biological variable, such as Escherichia coli, was not employed in the calculation because of the lack of prolonged monitoring data.

\section{Source identification}

The latent pollution sources were identified in the MS and NS sites using PCA. In the PCA calculation procedure, the factor with higher eigenvalue value indicated higher contribution. According to Liu et al. (2003), factor loading $>0.75$, $0.5-0.75$ and $<0.5$ was considered to be strong, moderate and weak, respectively. Communalities are estimates of the variance in each variable accounted for by the factors (Huang et al. 2009).

According to the values of communalities, potential pollution sources can explain all the pollution factors. In the MS sites, four varifactors (VF) explained $80.6 \%$ of the total variation. The first VF (VF1) accounted for $26.4 \%$ of the total variance, and VF2, VF3, and VF4 accounted for 21.7, 18.3 , and $14.2 \%$ of the total variance, respectively. In the NS sites, three VFs explained $78.4 \%$ of the total variance. VF1, VF2, and VF3 accounted for 49.9, 17.2, and 11.3\% of the total variance, respectively (Table 3).

In the MS sites, VF1 had a strong positive correlation with $\mathrm{NH}_{3}-\mathrm{N}, \mathrm{COD}_{\mathrm{Mn}}$ and $\mathrm{COD}$, and strong negative correlation with DO. These four pollution indices were related to pollution of oxygen consuming organics. Thus, VF1 represented oxygen consuming organic pollution from municipal sewage. VF2 had a strong positive correlation with $\mathrm{Cr}^{6+}$ and $\mathrm{Pb}$. The source of $\mathrm{Cr}^{6+}$ and $\mathrm{Pb}$ might be 
Table 3 | Varimax rotated factor loading in the two categories of monitoring sites ${ }^{\text {a }}$

\begin{tabular}{|c|c|c|c|c|c|c|c|c|c|}
\hline \multirow[b]{2}{*}{ Parameters } & \multicolumn{4}{|c|}{ Non-meeting standard sites ${ }^{c}$} & \multicolumn{5}{|c|}{ Meeting standard regions $\mathrm{s}^{\mathrm{d}}$} \\
\hline & & & VF3 & communalities & VF1 & & VF3 & VF4 & Communalities \\
\hline DO & -0.746 & -0.373 & & 0.766 & -0.746 & & 0.328 & -0.379 & 0.862 \\
\hline $\mathrm{COD}_{\mathrm{Mn}}$ & 0.636 & 0.708 & & 0.917 & 0.853 & & & & 0.784 \\
\hline $\mathrm{NH}_{3}-\mathrm{N}$ & & 0.895 & & 0.874 & 0.847 & & 0.436 & & 0.91 \\
\hline ТP & 0.532 & & 0.699 & 0.612 & & & 0.912 & & 0.861 \\
\hline COD & 0.788 & 0.348 & & 0.807 & 0.734 & & 0.506 & & 0.837 \\
\hline $\mathrm{Cr}^{6+}$ & 0.873 & & & 0.768 & & 0.881 & & & 0.824 \\
\hline $\mathrm{Hg}$ & & 0.804 & -0.318 & 0.818 & & & & 0.954 & 0.92 \\
\hline $\mathrm{Pb}$ & & & 0.94 & 0.898 & & 0.918 & & & 0.932 \\
\hline $\mathrm{F}^{-}$ & & 0.628 & & 0.528 & & -0.557 & 0.493 & 0.454 & 0.768 \\
\hline V-ArOH & 0.763 & 0.495 & & 0.856 & & -0.318 & 0.384 & & 0.358 \\
\hline Variance $(\%)$ & 49.9 & 17.2 & 11.3 & & 26.4 & 21.7 & 18.3 & 14.2 & \\
\hline
\end{tabular}

${ }^{a}$ Extraction Method: Principal Component Analysis. Rotation Method: Varimax with Kaiser Normalisation. Only factor loading values $>0.30$ are presented.

bVF: varifactor.

${ }^{\mathrm{C}}$ Rotation converged in 6 iterations.

${ }^{\mathrm{d}}$ Rotation converged in 6 iterations.

from soil erosion or runoff. $\mathrm{Cr}^{6+}$ and $\mathrm{Pb}$ levels at most monitoring sites were low. Thus we deduced that VF2 represented background values. VF3 had a strong positive correlation with TP. VF3 mainly represented non-point source pollution, e.g. erosion from agricultural land and urban runoff. VF4 had a strong positive correlation with $\mathrm{Hg}$ and moderate positive correlation with $\mathrm{F}^{-}$. It is known that wastewater from chemical industries, such as chemical plants, paper mills, and pesticide factories, contains $\mathrm{Hg}$. Thus, we deduced VF4 represented factors from wastewater of chemical industry.

In the NS sites, VF1 had a strong positive correlation with $\mathrm{COD}, \mathrm{Cr}^{6+}$, and $\mathrm{V}$-ArOH, and strong negative correlation with $\mathrm{DO}$, which indicated that water quality in this zone had been degraded by the presence of widespread anaerobic conditions, which was caused by the depletion of oxygen due to the decomposition of organic matter. It is well known that V-ArOH content is related to steel, coke, ammonia and other industries. Thus, VF1 represented pollution contribution from wastewater discharges of chemical industry. VF2 had a strong positive correlation with $\mathrm{NH}_{3}-\mathrm{N}, \mathrm{COD}_{\mathrm{Mn}}, \mathrm{Hg}$, and $\mathrm{F}^{-}$, and a moderate negative correlation with $\mathrm{DO} . \mathrm{NH}_{3}-\mathrm{N}, \mathrm{COD}_{\mathrm{Mn}}$ and DO related to pollution of oxygen consuming organics from municipal sewage. In addition, according to the survey of SBHWR in 2006, the average content of E. coli was $3,000 / 1$, which met drinking water standard. In the NS sites, the E. coli content was more than $20,000 / 1$ in urban, which did not meet the standard. The spatial distribution of E. coli was the same as $\mathrm{NH}_{3}-\mathrm{N}$. Thus, we assumed that VF2 represented oxygen consuming organic pollution from municipal sewage outlets. VF3 had a strong positive correlation with $\mathrm{Pb}$ and TP. $\mathrm{Pb}$ content was mainly influenced by natural factors and could enter the water body through runoff. At the same time, TP was also related to soil erosion and runoff. Therefore, VF3 mainly represented pollution contribution from non-point source.

\section{Source apportionment}

APCS-MLR was used to estimate contributions from the major pollution sources that were identified from PCA analysis. In the MS sites, four pollution sources had the proportion of contribution of 27, 30, 22 and $21 \%$ from municipal sewage, natural factors, agricultural non-point pollution and chemical industrial wastewater, respectively. Different pollution sources affected different hydrochemical parameters. Municipal sewage contributed $81.0 \%$ of $\mathrm{COD}_{\mathrm{Mn}}, 59.4 \%$ of $\mathrm{NH}_{3}-\mathrm{N}, 55.7 \%$ of $\mathrm{DO}$, and $36.5 \%$ of COD. The natural factor was the largest contributor to heavy metals, with the contribution of 80.1 and $82.2 \%$ to $\mathrm{Cr}^{6+}$ and $\mathrm{Pb}$, respectively. TP was mainly derived from agricultural runoff pollution (76.7\%). In the NS sites, the contribution of chemical industrial wastewater, municipal sewage and agriculture non-point pollution was 46, 33 and $21 \%$, respectively. Most variables were primarily influenced by industrial wastewater $\left(88.7 \%\right.$ for $\mathrm{Cr}^{6+}, 83.5 \%$ for 
V-ArOH, 83.0\% for COD, 69.2\% for DO, 52.5\% of TP), and municipal sewage $\left(76.6,70.5,66.3\right.$, and $47.2 \%$ for $\mathrm{NH}_{3}-\mathrm{N}$, $\mathrm{Hg}, \mathrm{F}^{-}$and $\mathrm{COD}_{\mathrm{Mn}}$, respectively).

In the MS sites, municipal sewage was the dominant pollution source. In the NS sites, the dominant pollution sources included both non-point source pollution, such as agricultural and urban runoff, and point source pollution, such as industrial wastewater and municipal sewage wastewater. The contribution rate of non-point source pollution in MS and NS sites was 22 and 21\%, respectively.

PCA and APCS-MLR worked well with identification of potential pollution sources in this study. The results were in line with the studies using factor analysis based on bio-indicators of structure and quantity distribution of ciliate populations (Zhang \& Yang 2008). However, PCA and APCS-MLR were unable to identify the specific source types, such as land use type related to non-point source pollution and the type of factories associated with point source pollution.

In our study, the effect from a few important factors was not analysed. First, effects from seasonal and inter-annual variations were not considered. We averaged the monitoring data for each site. Second, the identified sources from PCA analysis cannot explain all the variation, and more unknown sources should be considered in future study. Finally, soil types, watershed characteristics, terrain and other anthropogenic pollution sources need to be investigated in future study.

\section{CONCLUSIONS}

Our results in the Luanhe River basin demonstrated the discriminative power of the comprehensive method combining FCA, PCA and APCS-MLR in hydrochemical evaluation of surface water quality and pollution source apportionment. The results of FCA agreed with the general description of water quality that was reported by local river water quality mentoring centre SBHWR, which revealed that the pollution in the main channel was more serious than that in the tributaries. We classified all monitored sites into MS and NS sites. The PCA and APCS-MLR analyses showed that the pollution was mainly influenced by municipal sewage in MS sites, which contributed $30 \%$ to the total pollution; in the NS sites, chemical industry waste water contributed $46 \%$ to the total pollution. The priorities of the pollution migration in the Luanhe River basin should be the pollution control in the main stream and NS sites, and the management of wastewater discharge.

\section{ACKNOWLEDGEMENTS}

Funding was supported by One Hundred Talents Program of the Chinese Academy of Sciences, the National Natural Science Foundation of China (No. 41071323 \& 40971271), and the CAS/SAFEA International Partnership Program for Creative Research Teams of 'Ecosystem Processes and Services' (Grant No. KZCX2-YW-T13). The authors thank the water quality monitoring center of Chengde Branch of Hebei Provincial Survey Bureau of Hydrology \& Water Resources for providing monitoring data.

\section{REFERENCES}

Beketov, M. A. \& Liess, M. 2008 An indicator for effects of organic toxicants on lotic invertebrate communities: independence of confounding environmental factors over an extensive river continuum. Environ. Pollut. 156 (3), 980-987.

Farnham, I. M., Singh, A. K., Stetzenbach, K. J. \& Johannesson, K. H. 2002 Treatment of nondetects in multivariate analysis of groundwater geochemistry data. Chemometr. Intell. Lab. 60 (1-2), 265-281.

Huang, F., Wang, X. Q., Lou, L. P., Zhou, Z. Q. \& Wu, J. P. 2009 Spatial variation and source apportionment of water pollution in Qiantang River (China) using statistical techniques. Water Res. 44 (5), 1562-1572.

Jolliffe, I. T. 2002 Principal Component Analysis, 2nd edition. Springer-Verlag New York Inc. New York, $156 \mathrm{pp}$.

Kolovos, A., Christakos, G., Serre, M. L. \& Miller, C. T. 2002 Computational BME solution of a stochastic advectionreaction equation in the light of site-specific information. Water Resour. Res. 38 (12), 1318-1334.

Liu, C. W., Lin, K. H. \& Kuo, Y. M. 2003 Application of factor analysis in the assessment of groundwater quality in a Blackfoot disease area in Taiwan. Sci. Total Environ. 313 (1-3), 77-89.

Shen, G. Q., Lu, Y. T., Wang, M. N. \& Sun, Y. Q. 2005 Status and fuzzy comprehensive assessment of combined heavy metal and organo-chlorine pesticide pollution in the Taihu Lake region of China. J. Environ. Manage. 76 (4), 355-362.

Shrestha, S. \& Kazama, F. 2007 Assessment of surface water quality using multivariate statistical techniques: a case study of the Fuji river basin, Japan. Environ. Modell. Softw. 22 (4), 464-475.

Simeonov, V., Stratis, J. A., Samara, C., Zachariadis, G., Voutsa, D., Anthemidis, A., Sofoniou, M. \& Kouimtzis, Th. 2003 Assessment of the surface water quality in Northern Greece. Water Res. 37 (17), 4119-4124.

Sindosi, O. A., Katsoulis, B. D. \& Bartzokas, A. 2003 An objective definition of air mass types affecting Athens, Greece: the corresponding atmospheric pressure 
patterns and air pollution levels. Environ. Technol. 24 (8), 947-962.

Singh, K. P., Malik, A. \& Sinha, S. 2005 Water quality assessment and apportionment of pollution sources of Gomti river (India) using multivariate statistical techniques - a case study. Anal. Chim. Acta. 538 (1-2), 355-374.

Statheropoulos, A. M., Vassiliadis, N. \& Pappa, A. I998 Principal component and canonical analysis for examining air pollution and meteorological data. Atmos. Environ. 32 (6), 1087-1095.

Thurston, G. D. \& Spengler, J. D. I985 A qualitative assessment of source contributions to inhalable particulate matter pollution in metropolitan Boston. Atmos. Environ. 19 (1), 9-25.

Wang, X. Z., Shi, W. Z. \& Wang, S. L. 2003 Fuzzy Spatial Information Processing. Wuhan University Press, Wuhan, China, 122 pp.

Zhang, H. \& Yang, H. 2008 Assessment on water quality by structure and quantity distribution of ciliate population. Jiangsu Environ. Sci. \& Technol. 21 (supp.1), 64-66.

Zhou, F., Huang, G. H., Guo, H. C., Zhang, W. \& Hao, Z. J. 2007 Spatio-temporal patterns and source apportionment of coastal water pollution in eastern Hong Kong. Water Res. 41 (15), 3429-3439.

First received 12 January 2011; accepted in revised form 27 July 2011 